\title{
El Origen de los Sistemas Normativos. Una Propuesta desde la Moral Evolucionista ${ }^{1}$
}

\section{The Normative Systems' Origin. A Proposal from the Evolutionist Moral}

\author{
Camilo A. Sepúlveda* \\ Universidad Autónoma de Manizales \\ Universidad del Quindío \\ camilosepul@gmail.com
}

Fecha de recepción: 11 de marzo de 2014

Fecha de aceptación: 12 de mayo de 2014

\section{Resumen}

Nadie puede poner en duda que entre las características del ser humano se encuentra su naturaleza moral, y, muy probablemente, los sistemas normativos que el hombre en sociedad establece son el resultado de ella; sin embargo, no hay suficiente claridad acerca de cómo desarrollamos dicha naturaleza como especie humana. Una respuesta de tipo evolucionista sugeriría que si hay un rasgo característico distintivo en nosotros como especie debió ser el resultado de adaptaciones al medio en la lucha por sobrevivir. El objetivo de este artículo es revisar dos propuestas de este tipo, la de Ernst Tugendhat, según la cual los sistemas normativos son producto del desarrollo del lenguaje proposicional, y la de Richard Dawkins y su concepto de memes.

Palabras clave: Evolucionismo moral, Lenguaje proposicional, Memes, Sistemas normativos.

\footnotetext{
${ }^{1}$ Artículo de reflexión resultado del proyecto de tesis de grado para optar por el título de Magister en Filosofía moral y política, de la Universidad de Caldas.

* Universidad Autónoma de Manizales. Universidad del Quindío.
} 


\begin{abstract}
No one can't doubt that the moral nature is one of the human been characteristics and, probably, the regulatory systems that men in society sets are their result. However, it is not clear enough, how we develop such a nature as human kind. An evolutionary response may suggest that if we, as specie, have a characteristic feature, it should be the result of an environmental adaptation in the struggle to survive. This article's aim is to review two proposals of this kind: The Ernst Thugendhat's theory, whereby regulatory systems are the product of the propositional language development; and the Richard Dawkins's concept of memes.
\end{abstract}

Keywords: Memes, Moral Evolutionism, Propositional Language, Regulatory Systems.

\title{
Introducción
}

La reflexiones éticas, hasta hace poco, se habían limitado a tratar de establecer cuál era el comportamiento correcto, qué clase de acciones podían identificarse con el término bueno, a qué nos referimos cuando decimos Xes bueno, o si las expresiones morales tienen validez científica. La historia de la filosofía ha dado por sentado, y con razón, que eso que llamamos moral está inmerso inevitablemente en nuestras vidas, y que los esfuerzos teóricos deben ir dirigidos hacia establecer cuál es su naturaleza. También parecen partir del supuesto de que los seres humanos, al vivir en comunidad, nos sumimos en sistemas normativos. No parece pertinente preguntarnos acerca de la existencia o la no existencia de la moralidad o de dichos sistemas normativos, ya que, como diría Wittgenstein en su Tractatus (2010), las experiencias místicas (morales), hacen parte de la vida de las personas. Sin embargo, la pregunta por el origen de la moralidad sí parece tener coherencia, y su posible respuesta puede residir en un análisis de cómo, en términos evolutivos, el ser humano desarrolló la conciencia moral.

Si bien la teoría de la evolución y el darwinismo han servido como base teórica para diferentes áreas del conocimiento humano, la ética, tradicionalmente, no ha sido particular beneficiaria de este camino de análisis. A pesar de que la sociobiología ha pretendido aplicar la idea de selección natural a los fenómenos sociales y al comportamiento humano en sociedad, es decir, que la razón de los comportamientos humanos puede ser entendida en el contexto de la supervivencia de la especie, no ha habido un intento sistemático por explicar qué lugar ocupan 
nuestros sistemas de normas morales y nuestros sentimientos de aprobación o desaprobación frente al comportamiento de otros individuos; mucho menos cuál es la razón por la que hacemos distinciones entre lo correcto y lo incorrecto. Al respecto, el filósofo alemán (de origen checo) Ernst Tugendhat lanza una hipótesis a la que vale la pena prestar atención. Veamos.

\section{La Moral en Perspectiva Evolucionista}

En su libro Problemas (2002), Tugendhat recopila una serie de ensayos en los que indaga, como es su costumbre, acerca de diferentes problemas de índole filosóficos, entre ellos, el problema de la moral, su origen en el trayecto evolutivo humano, qué son y cómo se justifican los juicios morales y qué se entiende por moral. En uno de sus ensayos, La moral en perspectiva evolucionista (2002: 135), se propone intentar responder a la pregunta ¿de dónde nos viene la moral?, procurando no caer en una respuesta de tipo religiosa y llevando su rastreo más allá de un análisis histórico.

Acorde con una mirada evolucionista, y desde el punto de vista sociobiológico, es de suponer que si la moralidad es un rasgo característico humano, tuvo que haberse originado gracias a algún rasgo que representara una ventaja evolutiva y que facilitara su supervivencia respecto a otras especies animales. Parece evidente que la conciencia moral y la generación de sistemas de normas son exclusivas del ser humano. Pero, ¿qué condiciones pudieron provocar este rasgo distintivo? y ¿qué otras características exclusivas abrieron la puerta para el desarrollo de la moralidad?

La respuesta más inmediata parecería ser que la moralidad es el resultado de la convivencia en sociedad; si bien esto parece legítimo, no parece resolver el problema, ya que la vida en sociedad no es característica exclusiva y distintiva de los animales humanos. Ejemplos de especies animales que conviven socialmente y con aparente orden hay por montones. El hecho de que las hormigas tengan un sistema social no se traduce necesariamente en que el individuo hormiga haga distinciones entre lo correcto y lo incorrecto, y que con base en estas distinciones establezca sistemas normativos que contemplen sanciones y censuras.

Otros podrían argumentar que, además de la convivencia en sociedad, el desarrollo de sistemas de comunicación fue clave para el origen de la moralidad; por supuesto, de esto no cabe la menor duda; sin embargo, una vez más, este elemento es solamente parte de la respuesta, pero no responde por completo la pregunta, dado que, igualmente, existen diversas especies animales que tienen alguna forma de comunicación, que desarrollan estructuras sociales, pero en las que no hay la más mínima evidencia de conciencia moral. Las abejas, por ejemplo, han desarrollado formas de comunicación que se manifiestan en zumbidos y movimientos para señalar a sus compañeras las fuentes de alimentos o para alertar peligros inminentes, 
pero no hay evidencia alguna que sustente la idea de que las abejas han desarrollado sistemas morales.

La propuesta de Tugendhat va más allá de estos dos elementos. Para el filósofo alemán, el verdadero rasgo distintivo del ser humano es el desarrollo del pensamiento instrumental. Así, el pensamiento puesto en función como medio para la resolución de problemas y de búsqueda de alternativas para la supervivencia fue consecuencia del desarrollo del lenguaje proposicional.

Una forma de lenguaje en la que se puedan emitir proposiciones acerca de las cosas del mundo, o acerca de los pensamientos y los sentimientos, trajo como consecuencia la capacidad de considerar alternativas y opciones, y de confrontarlas consigo mismo y con otros miembros de la comunidad. Aún más, el lenguaje proposicional permite hacer distinciones claras y explícitas entre las creencias y los deseos o los sentimientos. Otros animales pueden expresar cosas sobre el mundo, y a esto podemos llamarlo comunicación. El ejemplo de las abejas es claro; su sistema comunicativo, no proposicional, les permite solamente comunicar cosas sobre el mundo; mientras que el lenguaje humano tiene funciones extracomunicativas: no solo comunica, sino que puede manifestar deseos.

...Ahora bien, la capacidad de pensar instrumentalmente es una consecuencia de la deliberación y de operar a base de razones. Así pues, lo que aquí se ha presentado como nuevo en la evolución posee la estructura más fundamental de la capacidad -posibilitada por el lenguaje proposicional-de preguntar por razones y de operar a base de razones (Tugendhat, 2002, p. 145).

Por otra parte, nuestras proposiciones acerca del mundo y acerca de nuestros deseos se ven confrontadas por las proposiciones de otros individuos, o con otras proposiciones que nosotros mismos podemos hacer, en las que planteamos alternativas. Las diferentes posiciones que se ponen en confrontación nos llevan a deliberar en busca de la mejor alternativa y a preguntar por las razones que sustentan dichas posiciones. Todo este uso comunicacional y sus consecuencias, según Tugendhat, constituyen la base de la racionalidad.

Tugendhat pone como ejemplo, para dejar clara la distinción entre el uso lingüístico de los humanos y de otras especies animales, un gato que sube a un árbol para ponerse a salvo de la persecución de un perro. Veamos:

Los seres humanos, debido a su lenguaje, poseen la capacidad de deliberar, y todo el que delibera pregunta por razones. ¿Cómo se ha de entender más exactamente la relación entre el lenguaje humano y esta 
capacidad? Cuando un gato es acosado por un perro y se sube a un árbol, explicamos su comportamiento como resultante de un deseo y de una creencia. Hace lo que hace porque quiere algo y cree algo (varias cosas), pero estos dos factores, querer y creer, no tienen en el gato representantes propios; el hecho de que, por el contrario, en los humanos se de tal separación entre deseos y creencias, es la consecuencia de que cada uno de estos factores pueda ser expresado lingüísticamente por separado. Lo peculiar del lenguaje humano ha de ser visto en su estructura proposicional, y las dos formas básicas son, de un lado, oraciones desiderativas, volitivas o imperativas y, de otro, oraciones que se expresan en opiniones (2002, p. 143).

Por supuesto que no pedimos explicaciones ni justificaciones para los enunciados que expresan cosas sobre el mundo. La justificación pertenece al ámbito de nuestros deseos, y son justificaciones de índole moral. No buscamos establecer la verdad o falsedad de las proposiciones acerca de deseos, sino de ponderar los deseos en relación con los deseos de los demás y con los propios.

La constante deliberación y las justificaciones que podemos dar acerca de nuestros deseos terminan por convertirse en sistemas normativos que rigen a una sociedad ${ }^{2}$. La sugerencia de Tugendhat es una suerte de contractualismo, y, en esa medida, ningún sujeto es ajeno al sistema, pues, de una u otra forma, como miembro de una sociedad y como especie participó en la deliberación que condujo al establecimiento del sistema.

De todas maneras, el paso de la deliberación al sistema normativo parece un salto abrupto y difícil de seguir. Queda por resolver cuáles son los motivos que nos hacen ponderar algunos deseos por encima de otros, que nos llevan a contraponer y comparar las proposiciones que podemos emitir acerca de unos y otros. Tal vez, otra teoría de carácter evolucionista pueda darnos una pista al respecto.

\section{El Gen Egoísta y los Memes de Dawkins}

En 1976, el etólogo, zoólogo y teórico del evolucionismo Richard Dawkins, publicó el libro El gen egoista, tal vez sin imaginar las repercusiones y la importancia que adquiriría su posición acerca del proceso de evolución natural. Manteniéndose en

\footnotetext{
${ }^{2}$ Sin embargo, parece que la idea de Tugendhat de que los sistemas normativos son el resultado de la deliberación, sugiere el establecimiento de una sociedad de personas libres capaces de hacer uso eficaz de su capacidad de deliberar. Podemos imaginar, de todas maneras, y de ello hay incontables ejemplos, sociedades en las que el sistema normativo está dado por imposiciones autoritarias religiosas o estatales, en las que el individuo solamente puede someterse al sistema. En el mismo libro, en su artículo No somos de alambre rígido, el autor llamará la atención sobre este aspecto llamando, al primer tipo de sociedad, sistema horizontal, y al segundo, sistema vertical (Tugendhat, 2002, p. 182).
} 
las bases del evolucionismo darwiniano, Dawkins propone que el sistema de selección natural no opera en la lucha entre especies por sobrevivir y por adaptarse al medio, sino que dicha selección natural actúa sobre los genes; así, según su teoría, la selección natural no era la responsable de la supervivencia de ciertas especies o familias o grupos o individuos, frente a sus competidores, sino que los genes del individuo mantenían una constante lucha por sobrevivir y por imponerse frente a otros genes y es ahí donde opera la selección natural. De esta manera, las variaciones genéticas de las especies eran el resultado de dicha confrontación. Los genes se esfuerzan por lograr la supervivencia de las especies porque con ella, como es obvio, aseguran su propia supervivencia.

A pesar de no ser Dawkins el primero en sugerir esta mirada sobre el concepto de selección natural darwiniano (él mismo da crédito de la teoría a W.D. Hamilton y a G.C. Williams), lo sistemático de su propuesta y el hecho de que haya llevado su sistema más allá de lo meramente biológico para proponer una alternativa acerca de las construcciones culturales, convirtió el libro El gen egoísta en un documento casi de culto en la reflexión evolutiva biológica y cultural.

En el capítulo 11 Dawkins introduce el revolucionario concepto de Memes, al analizar el fenómeno de la cultura desde el punto de vista evolutivo y en analogía con el comportamiento de selección natural genético. De esta manera, así como en el proceso biológico el gen es la unidad mínima con contenido de información heredable y que se enfrenta a otros genes con información diferente que así mismo buscan garantizar su supervivencia, transmitiéndola a sus sucesores, en la transmisión cultural también existe una unidad que opera de manera análoga; a esta unidad la llama memes.

"Mimeme" se deriva de una apropiada raíz griega, pero deseo un monosílabo que suene algo parecido a "gen". Espero que mis amigos clasicistas me perdonen si abrevio mimeme y lo dejo en meme. Si sirve de algún consuelo, cabe pensar, como otra alternativa, que se relaciona con "memoria" o con la palabra francesa même. En ingles debería pronunciarse "mi:m". (Dawkins, 1998, p. 211).

Un meme es una unidad replicadora de transmisión cultural; así, la cultura está compuesta de memes, de la misma manera que los organismos biológicos están compuestos por genes, que buscan sobrevivir transmitiendo su información de generación en generación. Al igual que los genes, algunos memes tienen características y son capaces de adaptarse al medio de tal manera que logren el éxito en términos de supervivencia; por esta razón, hay elementos culturales que han logrado sobrevivir a través de la historia gracias a que son más eficientes que otros 
que han perecido rápidamente. Los memes y los genes se encuentran en constante confrontación, en la que solamente se imponen los más eficaces. Todos los elementos de la cultura, según Dawkins, son el resultado de dicha confrontación.

Ejemplos de memes son: tonadas o sones, ideas, consignas, modas en cuanto a vestimenta, formas de fabricar vasijas o de construir arcos. Al igual que los genes se propagan en un acervo génico al saltar de un cuerpo a otro mediante los espermatozoides o los óvulos, así los memes se propagan en el acervo de memes al saltar de un cerebro a otro mediante un proceso que, considerado en su sentido más amplio, puede llamarse de imitación. Si un científico escucha o lee una buena idea, la transmite a sus colegas y estudiantes. La menciona en sus artículos y ponencias. Si la idea se hace popular, puede decirse que se ha propagado, esparciéndose de cerebro en cerebro (Dawkins, 1998, p. 212).

Por ejemplo, la idea de dios es un meme, una unidad cultural que ha sido exitosa y ha logrado sobrevivir a la confrontación con otros memes; prueba de ello es que ha permanecido viva desde tiempos remotos y su vigencia es incuestionable (una amplia porción de la población mundial cree en alguna forma de dios). En contrapartida, ha habido incontables ideas y construcciones culturales que han tenido una vida transitoria, e incluso mínima. Podríamos decir que en la batalla de la supervivencia, por ejemplo, el meme de la física newtoniana se impuso al meme de la física aristotélica.

Si bien Tugendhat manifiesta cierta crítica a Dawkins, en la medida en que no le dedica ni una de sus líneas a la reflexión acerca de la condición de moralidad de los animales humanos, ni cómo es que se genera tal cosa como la cultura, podría haber un vínculo entre las dos propuestas.

La idea del lenguaje proposicional como posibilitador de la moralidad, simplemente pone de manifiesto el origen de nuestra capacidad para intentar distinguir entre lo correcto y lo incorrecto, y las condiciones necesarias para establecer los sistemas normativos; sin embargo, y como manifesté anteriormente, lo que nos conduce a elegir y darle preponderancia a ciertos deseos sobre otros no es del todo claro.

Podemos suponer, basados en la teoría del gen egoísta, que lo que consideramos correcto o incorrecto, como elementos de la cultura, es resultado de un proceso evolutivo a través de memes. Tal vez los deseos a los que les damos mayor preponderancia son memes que han sido más exitosos o que son más fuertes que 
otros. Considerar el asesinato como incorrecto es un meme que se ha mantenido con vida, y en esa medida ocupa un lugar en nuestra jerarquización de deseos y de exigencias de justificaciones. De esta manera, se pueden establecer los sistemas normativos que rigen los límites que establecemos culturalmente como bueno y malo, como correcto e incorrecto.

Cuando se presenta la deliberación de la que habla Tugendhat, lo que está sucediendo, si atendemos a la idea de Dawkins, es que hay diferentes memes enfrentándose por sobrevivir. La selección natural, es decir, la capacidad de adaptación al medio se encargará de que prevalezcan unos elementos sobre otros en dicha deliberación.

Tugendhat, de todas maneras, sugiere que parte de la razón por la cual preferimos unos deseos sobre otros es que algunos nos conducen de manera más eficiente a la supervivencia como individuos y como especie; pero este elemento no difiere en ninguna medida de la propuesta de Dawkins. Podemos suponer que muchos memes que han logrado prevalecer, lo han hecho porque hacen más probable la supervivencia.

Lo que Tugendhat llama deliberación es, en la teoría evolutiva, la confrontación entre competidores en busca de la supervivencia. Cabría pensar, por tanto, que nuestros sistemas de valores morales, nuestros sistemas de normas, lo que nos conduce a la censura o al elogio, han sido el resultado de un conjunto de unidades (memes) que han salido victoriosos.

\section{Referencias}

Dawkins, R. (1990). El gen egoísta: las bases biológicas de nuestra conducta. Madrid: Salvat.

Elsdon-Bake F. (2009). The selfish genius: how Richard Dawkins rewrote Darwin's legacy. Londres: Icon books.

Stove, D. \& Kimball. R. (1995). Darwinian Fairytales: Selfish Genes, Errors of Heredity and Other Fables of Evolution. New York: Encounter Books.

Tugendhat, E. (1997). Lecciones de ética. Madrid: Gedisa.

Tugendhat, E. (2002). Problemas. Madrid: Gedisa.

Wilson, E. (1980). Sociobiología. Barcelona: Omega.

Wittgenstein, L. (2010) Tractatus lógico-philosophicus. Madrid: Alianza. 